\title{
¿En efecto no abortó el tiempo, o bien fue todo lo contrario? Racialidades y racismos en las relaciones interétnicas de la novelística de Crispín Amador Ramírez
}

\author{
Actually, was not Time Aborted? Or was it the Opposite? \\ Racialities and Racisms in the Relationships Between Ethnic \\ Groups in the Fiction of Crispin Amador Ramirez \\ Efetivamente não abortou o tempo, ou bem foi tudo o contrário? Racialidades \\ e racismos nas relações Inter étnicas da novelística de Crispín Amador Ramírez
}

\section{Arturo Arias}

THE UNIVERSITY OF TEXAS AT AUSTIN, ESTADOS UNIDOS

Profesor del Departamento de Español y Portugués, Universidad de Texas,

Austin. PhD en Sociología de la Literatura, Ecole des Hautes Etudes en

Sciences Sociales, París. Autor de La identidad de la palabra (Artemis \&

Edinter, 1998), Gestos ceremoniales (Artemis \& Edinter, 1998), la edición

crítica de Mulata de tal de Miguel Ángel Asturias (Archivos, 2001), The

Rigoberta Menchú Controversy (University of Minnesota Press, 2001)

y (University of Minnesota Press, 2007). Ganó dos veces el premio

Casa de las Américas y el premio Anna Seghers de Alemania por el

conjunto de su obra en 1990. Es Premio Nacional de Literatura Miguel

Ángel Asturias. Correo electrónico: arturo_arias@austin.utexas.edu

\footnotetext{
Artículo de reflexión

Este artículo forma parte del libro en preparación titulado preliminarmente Recovering Lost

Footprints: The Emergence of Contemporary Indigenous Narratives in Abya Yala.

Documento accesible en línea desde la siguiente dirección: http://revistas.javeriana.edu.co

doi: 10.11144/Javeriana.cl19-38.enat
} 


\section{Resumen}

El presente artículo propone nuevas categorías epistémicas desde las prácticas de lectura de las literaturas indígenas. Es importante validar no solo estos espacios experimentales que ocupan las narrativas escritas en lenguas indígenas sino el conjunto de este espacio geo-social ocupado por la indigeneidad contemporánea presuponiendo su mundo como fuente de literariedad, lo cual implica una ruptura con la ontología occidentalista y representa planteamientos frescos y estratégicamente críticos de nuevas prácticas decoloniales. Leer textualidades indígenas es en este caso una tarea sistémica acerca de la responsabilidad de lo ético coadyuvada por un compromiso epistemológico.

Palabras clave: otredad; imaginarios; etnoespacios; textualidades; decolonial; racializado; América Latina

\section{Abstract}

This article proposes new epistemic categories from the reading practices of indigenous literatures. It is important to validate not only the experimental spaces that written narratives occupy in the indigenous languages, but also the whole of this geo-social space occupied by contemporary indigeneity, assuming their world as a source of literarity. This implies a breaking with western ontology and represents new, strategically critic, approaches to new decolonial practices. In this case, reading indigenous textualities is a systemic task regarding the responsibility of what is ethic, with the contribution of an epistemological commitment.

\section{Keywords: otherness;} imaginaries; ethnical spaces; textualities; decolonial; racially divided; Latin America

\section{Resumo}

O presente artigo propõe novas categorias epistémicas desde as práticas de leitura das literaturas indígenas. É importante avaliar não apenas esses espaços experimentais que ocupam as narrativas escritas em línguas indígenas sino o conjunto de este espaço geo-social ocupado pela indigenidade contemporânea pressupondo seu mondo como fonte de literariedade, o qual implica ruptura com a ontologia ocidentalista e representa debruçamentos frescos e estrategicamente críticos de novas práticas decoloniais. Ler textualidades indígenas é, neste caso, uma tarefa sistémica ao redor da responsabilidade do ético coadjuvada por um compromisso epistemológico.

Palavras-chave: outredade; imaginários; etnoespaços; textualidades; decolonial; racializado; América Latina

RECIBIDO: 16 DE MAYO DE 2014. ACEPTADO: 22 DE JULIO DE 2014. DISPONIBLE EN LÍNEA: 01 DE JULIO DE 2015

\section{Cómo citar este artículo:}

Arias, Arturo. " ¿En efecto no abortó el tiempo, o bien fue todo lo contrario?

Racialidades y racismos en las relaciones interétnicas de la novelística

de Crispín Amador Ramírez". Cuadernos de Literatura 19.38 (2015):

293-317. http://dx.doi.org/10.11144/Javeriana.cl19-38.enat 
INOCENCI A D ISCURSIVA PODRÍA en efecto ser el cargo con el cual, quienes defienden el occidentalista esteticismo cosmopolita a ultranza, acusaran a las nuevas textualidades narrativas indígenas. No vemos en efecto en ellas ( ¡aún!) los deslumbrantes planteamientos metafísicos de un Borges, los juegos textuales y estrategias formales de un Cortázar, el bagaje de conocimiento europeísta de un Vargas Llosa. Felizmente tampoco vemos, hablando de este último, ningún rescoldo de utopías arcaicas, aquella malhadada etiqueta que el laureado limeño le impuso desdeñosamente a la "literatura social, indigenista y revolucionaria" ¿Qué es lo que vemos entonces? Vemos resistencias epistémicas al interior de las geografías de la exclusión y negación ciudadana, dada la realidad concreta sufrida por los ahora autores indígenas, análogo a residir en la base de la estructura piramidal de una sociedad de castas. Vemos nuevas prácticas discursivas modelando un complejo imaginario cultural como esfuerzo por sanar desigualdades racializadas.

Lo sabemos. Las textualidades narrativas emplean prácticas discursivas y modos figurativos articulando regímenes de conocimiento por medio de estructuras gustativas. Las nuevas textualidades indígenas -ninguna anterior a 1970- se encuentran en este momento inventando estructuras escriturales, valga la redundancia, para captar o comprender lo que aún no han pensado ni siquiera importantes sectores poblacionales latinoamericanos: que existen objetos denominados "novelas" escritos en lenguajes "crípticos" para el monologismo hispanohablante, articulando sistemas experimentales que por medio del lenguaje fabrican modelos culturales para explorar, darle forma y generar formas emergentes de subjetividad como mecanismos de auto-validación y de agenciamiento político ${ }^{1}$.

El tiempo no abortó / Tonali amo tlanki (2008) es en palabras de su autor, Crispín Amador Ramírez, una,

[...] expresión de emociones y sentimientos albergando un cúmulo cultural de pensamiento nauatl, convertido en modo de vida aprendido de los ueues [ancianos principales; na] a través del largo proceso de experiencias en lengua

1 Pienso en 1970 como el año de escritura, pero no de publicación, de El tiempo principia en Xibalbá del autor maya kaqchikel Luis de Lión (1939-1984), la cual no fue publicada sino póstumamente en 1985. Sin embargo recién me entero de la existencia de una novela colombiana titulada, Los dolores de una raza de Antonio Joaquín López, escritor wayúu, publicada en 1956. Esta podría ser considerada la primera novela escrita por un indígena en las Américas, dado que el autor estadounidense N. Scott Momaday publicó House Made of Dawn en 1968. Desafortunadamente la circulación de la novela de López ha sido tan restringida que costaría articular una genealogía a partir de su existencia. 
étnica $[. .$.$] que se vierten desde el corazón, y se vuelven hechos, actos y fenó-$ menos sociales. $(9)^{2}$

Es eso. Y es mucho más. Es una ruptura epistemológica con varios axiomas: con aquel afirmando que los idiomas nacionales de los países del continente (con la excepción del Brasil, Belice, Haití, Guyana y Surinam) sea el castellano, por ejemplo. O bien la afirmación de que los idiomas indígenas son un resabio del pasado prehispánico, como elemento que suele añadirse al hispano-centrismo. Pero guste o no, su producción narrativa desmitifica la noción racista de que los indígenas son analfabetos y viven inmersos "tan solo" al interior de culturas orales, expresión despectiva articulada por una visión del mundo eurocéntrica, racializada, ofensiva, caduca.

Desde hace ya más de quince años, Gabriele Schwab argumentó la necesidad de emplear los contactos culturales en su sentido más dinámico como marco heurístico para resaltar y recalcar las transacciones o negociaciones acontecidas entre lectores y textos, textos y contextos, teorías y otros textos (Schwab, The mirror 10$)^{3}$. Hasta cierto punto evoca la recomendación bajtiniana de que para comprender la otredad, es importante que el sujeto dialogante se ubique fuera del objeto de su comprensión en tiempo, espacio y cultura, porque según Bakhtin es solo ante los ojos de otra cultura que la otredad puede revelarse a sí misma de manera profunda.

El pensador ruso nos recordó asimismo que la relación dialógica entre las culturas no resulta ni en fusión ni en mezcla, sino que cada una retiene su propia unidad y características, pero ambas se enriquecen mutuamente (Bakhtin 7). Schwab retoma algunos de estos aspectos para argumentar que es solo en las lecturas de textos otros que el lector consigue percibirse desde fuera, tanto como sujeto así como en la propia carnalidad de ser otro. Lo anterior la lleva a explorar las relaciones de trasferencia y contacto en las lecturas literarias para explorar las conexiones entre esferas retóricas, culturales y psicológicas. A ella le interesan efectos de realidad de índole psicológicos. Por ello le atrajeron los catexis afectivos articulados en los imaginarios representados discursivamente, entendiendo por ellos la unión de energía psíquica, su carga e impulsos, a una representación o grupo de representaciones. Sin embargo en ese proceso llegó también a argumentar su propia

2 A partir de este punto escribiremos nauatl como lo hace el autor, en vez de náhuatl, como parecería mandarlo la Real Academia Española de la Lengua, priorizando la articulación del sujeto hablante de este idioma.

3 Esta investigación continúa en su última publicación, Imaginary Ethnographies. 
otredad en tanto que enunciación escritural, en relación con otras prácticas discursivas (Schwab, The mirror x). Asimismo, no limitó su articulación de lo entendido por contacto cultural a encuentros entre sujetos de diferentes culturas, sino incluyó los procesos socializando a los lectores en función de ambientes culturales específicos, los cuales modifican así su relación singular con su propia cultura. Esto último también evoca las fronteras del lenguaje mismo en tanto que articulación subjetiva.

En un mundo cosmopolita globalizado, las discursividades literarias ya no jugarían un papel crucial en los procesos de aculturación, dado a cómo la imaginería tecnológica ha suplantado brutalmente el acto de leer (libros, por lo menos) como mecanismo de acceso. Pero en los contactos entre indigeneidades y occidentalidad continúan jugando un papel crucial. La representación escritural de un lenguaje indígena, por mucho que sea percibida tan solo como presencia semiótica incomprendida por el lector mono-occidental, transgrede las fronteras culturales presupuestas por el mestizaje y modifica sus códigos, posicionando así patrones que facilitan los contactos interculturales.

Lo anterior dificulta felizmente la aplicación mecanicista de teorías en los estudios de textualidades indígenas. El acto crítico se convierte en un gesto performativo, a manera de señalar, de manera un tanto catacrésica, las mismas digresiones inesperadas, articulando los signos que intentan redimir y celebrar etnoespacios desconocidos que ponen el ordenamiento del mundo neoliberal en estado de caos, próximo a la abyección como sabemos, al saturar la lógica occidental desde la perspectiva de lenguajes otros, cuestionando el horizonte de expectativas eurocéntrico, forzándolo a entablar contacto con conocimientos distintos, tácitos, a veces aún carentes de estrategias retóricas solventes, lo que la misma Schwab denomina etnografías imaginarias en su último libro. El choque escritural es fuerte dado que los espacios fantasmáticos organizando las percepciones culturales de las mentalidades hegemónicas insertas dentro de los parámetros de la colonialidad del poder, continúan ¡aún!, concibiendo la indigeneidad con patrones asociados a una percibida barbarie que les obliga a quienes consideran las tierras originariamente indígenas "suyas", a organizarse en torno a una economía del miedo interiorizada ya en su libido. A estas alturas del siglo XXI los indígenas son aún sobre-determinados en el seno de diversas sociedades latinoamericanas como los primordiales seres canibalescos de los sueños arcaicos del inconsciente geopolítico.

En un artículo sobre escritura, lenguaje y etnicidad, el lingüista Sergio Romero argumenta que existen formas alternativas de imaginar y articular la comunidad étnica y su producción textual. Agrega: 
Las tensiones y complicidades entre ellas refleja el tortuoso y complejo proceso de resistencia y adaptación a las fuerzas de la globalización en un oecumene q'eqchi' cada vez más complejo en los altos y bajos de Guatemala (Romero 7) . $^{4}$

Extendiendo la observación anterior a diversos contextos mesoamericanos, enfocaré en este artículo cómo aparecen las mencionadas tensiones y complicidades en el enrevesado proceso de resistencia y adaptación comunitaria articulado por Crispín Amador Ramírez en su segunda novela El tiempo no abortó / Tonali amo tlanki (2008). Para ello interconectaré, cuando no fusionaré de manera un tanto provocadora, pero justificada ética y metodológicamente, por lo cual no presento coartada ni excusa alguna, los conocimientos otros de origen indígena con las teorías posestructuralistas. No solo tenemos que hacerlo profesionalmente para sobrevivir en un momento en el cual nos están cerrando literalmente los espacios humanísticos en las universidades -y sería hipócrita negarlo- y también eleva el nivel de nuestra credibilidad. Con ello visibilizamos más y mejor las discursividades, lenguajes y culturas que estudiamos. Será pues mi consigna a partir de ahora un proceso de clasificar, seleccionar y narrar materiales críticamente vírgenes en un rito iniciático, conduciéndolos hacia su bautizo hermenéutico, el cual incluye desde luego su teorización.

\section{El tiempo, ¿abortó?}

El relato de esta textualidad narrativa se desarrolla en la Huasteca hidalguense. Es ese su domicilio. La topología privilegiada. Allí transcurre la etnografía imaginaria. En su sentido más simple, plasma lo visto y sentido ahí, en estos lugares periféricos del cosmopolitismo "chilango" (de la capital mexicana) donde, según la nota periodística promocionando la novela,

[...] el día a día se vive sin prisas, donde sus habitantes se procuran el alimento diario y a veces no hay más que dos tortillas para toda la familia. Beto y Lupe, protagonistas de esta historia, dan vida a la palabra, la convierten en un puente entre ellos y el exterior, y sobre todo, en un lazo que los hermana. Hay que enfatizar que en este texto no se idealiza al indígena, por el contrario, se le dota de humanidad, es un ser tanto con virtudes como con defectos. (Notimex)

4 "The tensions and complicities among them mirror the tortuous and complex process of resistance and adaptation to the forces of globalization in an increasingly complex Q'eqchi' oecumene in highland and lowland Guatemala" (Romero). 
Pero las textualidades narrativas nunca son tan pastoralmente simplistas. Ninguna articulación de signos lingüísticos lo es, por mucho que lo pretenda y se esfuerce en serlo. Para empezar, no olvidemos. Este es un texto escrito en nauatl. Ni siquiera en náhuatl. Como ya indiqué en un artículo anterior, Crispín Amador Ramírez es co-autor de un vocabulario nauatl-español (sin " $h$ "), y autor de Tlajtolchiuali, palabra en movimiento: el verbo (2002) $)^{5}$. Señalaba de igual manera que El tiempo no abortó tiene por título en nauatl Tonali Amo Tlanki, lo cual significaría "tiempo", "vía", y "destino que no acabó". Esto inmediatamente genera dos problemas. Primero, tomado literalmente, significa lo opuesto del título en castellano. "El tiempo no abortó" implicaría que el transcurso del tiempo llegó a su conclusión. Sin embargo la versión nauatl del título significa lo opuesto en su tlajtolchiuali o forma verbal, según el mismo autor:

tonali= tiempo, destino, vida, se llega a entender como camino al referirse a la vida

amo= negación

tlanki= terminar en tiempo pasado simple en la variante de la huasteca (región en la zona limítrofe de Hidalgo, San Luis Potosí, Tamaulipas y Veracruz)

Efectivamente es así como señalas porque el verbo interrumpir no existe entonces al decir la vida o destino que no terminó; se concibe como que se interrumpió, no llegó a su fin, qué pues, la vida. (correspondencia con el autor, 14 de enero 2013)

En castellano entonces, la línea temporal de la historia narrada llega a su final esperado. En nauatl sucedería lo contrario. Mejor ejemplo de la ambigüedad o característica circunstancial en una traducción que se resiste a ser traducida, guardando secretos en su lengua original, es imposible7. "Tlanki" y "abortó" son un evidente oxímoron bilingüe. Asimismo y como segundo punto problemático en la traducción del título, no estaría presente tampoco la imagen de "abortar",

5 "Nahuahtlizando la novelística: De infiernos, paraísos y rupturas de estereotipos en las prácticas discursivas decoloniales".

6 Crispín Amador Ramírez nació en San Isidro, Atlapexco, estado de Hidalgo en 1965. Terminó la escuela primaria sin hablar castellano. Estudió la escuela secundaria interno en un instituto de varones donde aprendió el castellano y empezó a participar en círculos de lectura. Completó el bachillerato en fruticultura tropical. Es licenciado en educación media en el área de ciencias naturales por la Escuela Normal Superior de Hidalgo. Sin embargo trabajó en programas de campo antes de ser docente, como promotor agrario. También fue obrero.

7 Entiendo aquí secretos en el sentido empleado por Doris Sommer (1991) en su artículo seminal de los noventa del siglo pasado como resistencia ético-estética de los hablantes indígenas para mantener la comprensión eurocéntrica hegemónica de su mundo íntimo a distancia. 
asociada en el mundo cosmopolita a la extracción o expulsión de un feto, término que reinscribe la noción castellana dentro de la metafísica cristiana. Si la traducción normal entre lenguajes occidentales implicaría el conservar el mismo significado para diferentes significantes, la traducción a y de los idiomas indígenas implica no solo diferentes significantes sino también diferentes significados conceptuales para así marcar diferencias metafísicas.

Pasada esta problematización inicial, cuando no iniciática en cuanto a las prácticas discursivas decoloniales, sobre la cual volveremos hacia el final del artículo para ahondar en su contradicción, tenemos también el asunto de la trama. No es cualquier cosa. "Beto y Lupe son los personajes que trazan el gran escenario de esta narración" (Ramírez 9), nos dice el autor en su breve introducción. Pero agrega de paso unas frasecitas intentando pasar desapercibidas, tímidas, caminando de puntillas como si nada, signos buscando invisibilizarse. Dice, "“[..] Beto que procede de familia indígena campesina holgada y preferencia social entre seis hermanas, tiene un encuentro inesperado con Lupe, quien no es indígena, pero sí campesina" (10, cursivas del autor).. Una relación interétnica para empezar. Una relación sobre la cual los padres desaprueban. Una relación bilingüe, ya que la mestiza Lupe no habla nauatl. Un texto que traducirá del castellano al nauatl los diálogos de una de sus dos personajes principales. El contacto cultural impactando las fronteras entre las culturas. De entrada un terremoto sacude este texto. Rompe aun antes de iniciarse las presunciones de lo que podría constituir un texto decolonial escrito en lengua indígena. Más tarde veremos también la engorrosa significación de los vocablos "familia indígena holgada". No se compara con lo que entenderíamos en un contexto cosmopolita por el participio holgado, interpretado habitualmente como encontrarse en una situación de desahogo, con recursos suficientes para vivir bien.

La focalización interna del narrador autodiegético nos relata en tanto que lectores, que Beto la conoce en el pueblo donde vendían frijoles con su padre un mes de diciembre. Ya casi terminada la venta el chico de quince años tiene sed. Su padre le da dinero para comprarse un refresco en la tienda. Entonces nos dice el texto, "miré hacia una tienda abierta [...] pero más me llamó la atención la muchacha que atendía" (92). Inmediatamente surge su conciencia étnica cuando él transpone la mirada de ella y se mira a sí mismo como lo miraría ella: "[...] ella desde adentro me miraba al llegar a la puerta me detuve, miré mis guaraches, mi ropa de manta, me quité el sombrero de palma, me acordé que yo no hablaba castellano $[\ldots] "(92)$.

La descripción de la voz narrativa se centra a continuación en el intercambio entre ambos. Ella lo mira de reojo. Él se encuentra convertido en un manojo de 
nervios balbuceando lo que desea. Surge entonces la segunda alusión de índole étnica en la perspectiva de su propia observación. Ella tenía "ojos claros, labios gruesos y rojos, le caían unos caireles [...]" (92) Enseguida se bebe el refresco casi de un sorbo. Ella lo miraba. Él se puso aún más nervioso. Terminó el refresco, la miró a los ojos, le dio la mano para despedirse y ella se la devolvió. Él sintió su mano suave en la suya, percibió el contacto de su piel y se le erizaron los pelos al sentir un deseo aún incapaz de conceptualizar. Enseguida se marchó, el sudor escurriéndose por la columna vertebral, la respiración agitada. Entonces aparece la última observación de índole étnica. Beto piensa, " [...] pero ¿cómo hacerle? Ella seguramente no habla mi lengua y yo tampoco el castellano" (92).

Eso es todo. Pero es mucho. El sujeto, Beto, modela su propia percepción en la mirada racializada que lo definiría desde fuera en tanto que indígena. Es decir, se ve a sí mismo como menos que un mestizo, como si presumiera de un juicio metafísico que, aspirando a un estado de focalización cero, trascendiera la mirada de la joven Lupe. Hasta este punto de la narración ya hemos recorrido dos secciones del texto, ambas sobre la infancia de los personajes interactuando en el segmento citado, ambos narrados autodiegéticamente, es decir, en primera persona. Describen el hambre y pobreza sufrida por Lupe y su familia. La holganza de Beto, niño travieso con tiempo entre sus manos. Pero no racismo. Entonces, ¿ cómo surge esta conciencia repentina en el joven Beto, en el momento de sentirse mirado por una joven ladina, una mestiza (acerca de la cual no sabe que es más pobre que él)? ${ }_{\mathrm{C}}$ Una omisión mental de la voz narrativa? ${ }_{\mathrm{d}} \mathrm{O}$ bien algo que está tan presente, tan arraigado, forma una parte tan integral del paisaje cultural, el etnoespacio en el cual operan estos personajes, que a la voz narrativa no se le ocurrió nunca nombrarlo hasta el instante en el cual confronta la afectividad? ¿Cuándo "a mis quince años sentía por primera vez algo que jamás sentí, no sé si era gusto, pero hasta quería bailar?" (92). Lo anterior marca a Beto. Lo marca afectivamente pero lo señala también al evocarle una racialidad interiorizada en su propio ser. Exterioriza una conciencia de ser otro frente a la guapa joven.

En esta misma escena, fortuita dado que Beto acompañó a su padre tan solo porque este último no tenía un peón disponible, Lupe actúa en su accionar la palabra amabilidad que aprendió años antes en la escuela de boca del maestro, "palabras que nunca había escuchado" (30). El evento en el cual se conocen evoca la palabra aprendida del maestro sin nombrarla. Es decir, evoca su significación aprehendida más que el significante original. De esta misma manera, sin duda, Beto aprendió e interiorizó el racismo. Porque en efecto, luego de esa escena, es decir, uno o dos meses después en la cronología, el narrador autodiegético nos informa que le pidió a su padre asistir a la escuela para "aprender a leer y 
escribir" (104) con la intención de volver a verla. El padre responde que "no somos coyomej, no vamos a vivir en la ciudad". Coyomej es un ladino, un mestizo, un citadino no indígena. Lo dice el mismo glosario del texto (405). El término marca con fuerza la racialidad. Beto y familia no son coyomej. Su identidad no es nombrada pero sí se dice lo que no son y lo que no hacen: hablar castellano. Eso último se repite en este breve capítulo. Beto se va a la escuela donde "los demás niños olían bonito" (106) y recibió "dos castigos hincado en la arena por no contestar algo que nunca entendí por no hablar castellano" (106). Analépticamente nos enteramos que Beto siempre supo del racismo y lo interiorizó pese a su condición económica superior. Pero el mismo solo es escenificado en el acontecimiento del encuentro que altera las subsecuentes acciones de estos actores.

El encuentro casi se transforma en desencuentro. Lupe ya no vuelve a la ciudad. Nos enteramos con posterioridad que sus padres insistieron en que estudiara para maestra. Beto ya no la vio. A los 17 años le entró "la terquedad" de aprender el castellano (114). Decide entonces marcharse a Querétaro. La función del viaje mismo sirve como secuencia indicadora de otro elemento racializado. Se va vestido con su "calzón", la ropa de manta típica de los indígenas de la zona, marcándolo como diferenciado del resto de la población occidentalizada. En Querétaro es rechazado. Se ve obligado a volver a su aldea donde, para su sorpresa, ya han contratado una maestra. La misma resulta ser Lupe, segundo acontecimiento crucial de la serie afectiva.

El reencuentro favorece la relación temporalmente. Pero entonces descubrimos un gesto inicial de racismo al revés, cuando no de "multirracismo" como decía Hale para una zona de Guatemala (295). Para la madre de Beto, la maestra era "la xinula" (132), o sea, la citadina, la mujer no indígena de acuerdo al glosario (405). Esto se repetirá luego cuando Beto afirma, "Ella me había dicho que sus padres no me querían por que (sic) era un indio de bragueta cruzada, eso decían por que usaba calzones de manta, en mi casa no la querían porque era xinula [...]" (144).

Producto de la colonialidad del poder, el racismo es la sombra persiguiendo a todos estos personajes, generándoles una dependencia subordinada, y subordinándolos a su vez, sometiéndolos en el mismo. Es una subordinación en la cual dependen para su misma existencia. Casi parece un apego emocional, una regulación imposible de suprimir que autoriza y disuelve hasta cierto punto su existencia, imposibilitando su sanación. El sujeto parecería emerger bajo la condición de tener que reafirmar el racismo como si fuera este el resultado de sus mismas condiciones de posibilidad. Aquí es representado como un discurso injurioso amenazando con alterar su validación como sujeto precisamente por esa 
imparable búsqueda inconsciente que conlleva, en su expresión visceral, su misma aniquilación en el momento mismo de repetir neuróticamente la performatividad de los escenarios primarios del racismo ${ }^{8}$. Es como diría Butler, parafraseando a Hegel, la transmutación del amo en la realidad psíquica del esclavo (3). En este mismo sentido podemos asumir a priori, desde luego, que el "racismo al revés", como se ha documentado en otras instancias por la vía antropológica, estaría asociado a un empoderamiento económico por parte de sectores indígenas, los cuales sobre esta base elaboran reivindicaciones de índole socio-cultural ${ }^{9}$. Está presente sin duda cierta forma de criptomnesia visceral asimismo, en la cual los mismos discursos racistas de los sectores hegemónicos son reensamblados, re transcritos y re categorizados por los sujetos injuriados, quienes los transforman en instrumentos de agenciamiento como efecto de su misma subordinación. Finalmente, las condiciones irreconciliables como las manifestadas aquí por Beto y Lupe en oposición a la visión de sus padres como guardianes simbólicos de los valores tradicionales de la comunidad, conducen a la polarización, antagonismo y conflicto mutuo, como señalaron Balibar y Wallerstein del "efecto de carrousel" (Balibar y Wallerstein 1991).

Afecta a Beto y Lupe sin embargo. Los primos de Lupe dicen que "no entra ningún indio de bragueta cruzada a su familia" (146). Con anterioridad ella es transferida como maestra estando embarazada. El último dato mencionado surge en el texto de manera tan sorpresiva como en este artículo. Se lo cuenta Beto a su amigo Tomás (144). Hasta ese punto, como lectores apenas sabíamos que cuando Beto le propuso ser su novia, ella le dijo "no", agregando que tenía novio en su pueblo (136). La duración narrativa temporal está permeada de estos gestos. Tiempos narrativos largos representados en cortos tiempos discursivos en los cuales nos enteramos a posteriori de la trascendencia de lo no relatado. Por ejemplo, esto mismo vuelve a suceder cuando nos enteramos que "nació mi hijo" (230). Sabíamos que la segunda preñez había generado un hijo pero no se había vuelto a mencionar el dato. Solo aquí nos enteramos. Pero luego de lo anterior, la voz narrativa agrega que "me emocionó mucho porque el anterior había muerto" (230). Esta última información permaneció escondida, con el dolor de perder al primer hijo varón que esto conlleva en el imaginario cultural de la sociedad en cuestión para un padre. Es como si se representara en el relato mismo el proceso de esconder secretos personales

8 Estas elaboraciones vinculadas a la performatividad emergen de mi lectura de The Psychic Life of Power de Judith Butler.

9 Ver en el caso guatemalteco "El discurso ladino del racismo al revés en Guatemala", de Charles R. Hale en Arenas, Hale y Palma Murga, ¿ Racismo en Guatemala?, a manera de ejemplo. 
cargados emotivamente hasta que su revelación pública se convierte en inevitable por razones ulteriores a lo acontecido. Sin embargo, esto último siempre sucede tiempo después de acaecido el evento crítico en cuestión. Reordena así el texto la temporalidad de los eventos como mecanismo cultural, actuando hasta cierto punto como mise en abyme de las condiciones culturales del sujeto racializado. Son para el lector, para el sector hegemónico occidentalizado de la nación, sujetos invisibles, culturas invisibilizadas. Solo les reconocen, les reconocemos en tanto que lectores, su visibilidad en experiencias-límite en las cuales ya no tenemos remedio más allá de admitir públicamente lo acontecido.

Lupe da luz a una niña. Su padre, Juan, está "que se lo lleva el diablo" (152) al enterarse que Beto es el padre. Cuando este llega al pueblo se ampara ante la autoridad, temiendo la violencia de su oponente. Asimismo entrega una suma de dinero para mantener a su mujer y a su hija. El juez lo reconoce y se compromete a ayudarlo. Cuando llega Juan, pese a encontrarse ante el juez, grita que "Yo no quiero que mi hija se case con cualquiera, mucho menos con un indio pata rajada" (160) e intenta agredir físicamente a Beto. Los policías tienen que retenerlo. El juez lo obliga a llevarse el dinero y a darle libertad a su hija para casarse. Al inicio aún viven separados pero luego que la niña se enferma deciden casarse y Lupe se marcha con Beto. Al casamiento civil solo asiste la madre de Lupe, pues ni su padre ni los de Beto aprueban el matrimonio. Cuando la lleva a su casa los padres de Beto "la dejaron con la mano tendida porque no le contestaron" (178) cuando ella los saludó. A partir de este punto se desencadenarán los "sucesos posmatrimoniales" (177) que marcarán la segunda mitad del texto.

El texto está dividido en la introducción más doce partes, para un total de trece, el número de cielos de la cosmovisión mesoamericana ${ }^{10}$. Cada una de estas partes corresponde a un estadio en la relación de Beto y Lupe, si aceptamos

10 Los trece cielos en la mitología mexica son el resultado de la cabeza de Cipactli. Su cuerpo representa la forma que los dioses le dan al universo. Sus niveles representan la región vertical del universo. Las fuerzas superiores e inferiores convergen en la tierra, a la cual influencian. Los cuerpos celestes caen al inframundo y emergen de él a diario, siendo definidos por los cuatro puntos cardinales y las fuerzas que emanan de ellos. La tierra es sostenida por un eje al centro donde convergen esas fuerzas. Sus regidores son Tezcatlipoca (Norte), Xipetótec y/o Tláloc (Este), Quetzalcóatl (Oeste), Huitzilopochtli (Sur). El centro de la tierra está gobernado por Xiuhtecuhtli (Centro), siendo el punto de unión de la tierra y del cielo, de los cuatro rumbos del mundo, el mundo superior e inferior. De esta forma, el organismo humano está inserto en el cosmos y forma parte de los cinco elementos junto con el aire, la tierra, el fuego y el agua. Ver Dioses Prehispánicos de México de Adela Fernández y La filosofía náhuatl estudiada en sus fuentes de Miguel León-Portilla. Sobra decir que esta misma mitología, con diferentes nombres, impera en el mundo maya. 
la introducción, con su carácter paratextual marcando la recepción del relato por medio de la divulgación de la naturaleza interétnica de la relación de estos últimos, ese umbral localizado en la misma zona intersticial luego representada por el relato en tanto que narratividad, la transición que es también la zona de transacción en palabras de Genette (2), ese estratégico mercado pragmático en el cual se regatea la naturaleza de la recepción del texto y su lectura más pertinente, desde el cual se intenta controlar su misma lectura, como la primera de ellas ${ }^{11}$. Las otras doce corresponden a las diferentes etapas de su niñez y de su convergencia como adultos. "Infancia sin niñez" ("Piltonyotl amo ika koneyotl") narra las miserables desventuras de Lupe mientras crecía en una zona aledaña a Tenexco en la huasteca hidalguense, cerca de la frontera con el estado de Veracruz. Su contrapartida es "Infancia de más" ("Achi ueyi piltonyotl"), la acomodada niñez de Beto sin tener que trabajar en la milpa. Sigue a continuación "El encuentro" ("Kampa mo pantiaj") previamente descrito.

A partir de allí los títulos de las diferentes partes serán los mejores indicativos del paso del tiempo narrativo, señales tangibles del marcaje calendárico de un ciclo de vidas circunscritas al tiempo como corresponde en el mundo mesoamericano enraizado en el cosmos. Recordemos que las poblaciones mesoamericanas son famosas por sus calendarios precisos y su conocimiento de la astronomía, y desarrollaron calendarios complejos y precisos que siguen marcando los ciclos agrícolas y ceremoniales. Luego del encuentro tenemos entonces "El casamiento" ("Tlasiuajtili"). En seguida "Primeros sucesos posmatrimoniales" ("San mo siuatijkej achtoui tlamanimej"). Luego aparece "La vida de pareja" ("Omeya in tonal"). A continuación "Los hijos se van" ("To koneua tech kajteua"). La siguiente parte se titula "La pareja queda sola" ("Mo kaua in selti te tatua"). Seguidamente, "Estoy contento por mis hijos" ("I pampa no koneua ni yolpaki"). Posteriormente, "La salud se debilita" ("Yolchikajtli sotlauia"). Aparece después "Las diferencias" ("Xeloli") y finalmente "La vida cambia" ("To tonal mo patla").

$\mathrm{Al}$ examinar este listado se alumbra retóricamente el paso del tiempo en las vidas de la pareja al interior de la tradición mesoamericana. El tiempo está conectado a los ciclos naturales de la tierra y del cielo. Desde esta perspectiva, como sabemos, el sol, el maíz y el calendario están interrelacionados. El sentido del tiempo está desde luego basado en entender ciclos recurrentes. Esto incluye el movimiento observable del sol, las fases de la luna, el período de gestación de los seres humanos y el ciclo de crecimiento del maíz. Por ello en las tierras altas de Guatemala los contadores del calendario maya describen el tiempo como un atributo de lo sagrado. Todos estos

11 Ver la introducción de Paratexts: Thresholds of interpretation de Gérard Genette. 
elementos inventariados aquí constituyen la matriz mesoamericana, determinando la continuidad de los ciclos de vida y de muerte.

La contemplación del índice como afiliación contextual articulado empíricamente como agrupación cuasi heterogénea de prácticas discursivas, conjuntos de enunciaciones convergiendo en un efecto holístico, genera la sensación calendárica de que lo representado ya estaba destinado a suceder en este modelo alternativo de organización comunitaria (y retórica), como característica definitoria de los individuos poblando el texto. Al fin y al cabo sus lectores ya están informados de que este es un autor indígena y están expuestos en cada página impar al inaccesible discurso original en nauatl. Conocimiento de estos elementos pragmáticos y programáticos inevitablemente informan la lectura, transformándola en un acto ilocucionario, produciendo el efecto perlocutivo en la lectura, de idealizar afectivamente, pero con un romántico efecto arcaizante que subvalora a los sujetos, la supuesta comunidad representada ${ }^{12}$.

Lo anterior es una premisa divergente de la realidad textual que yo enfatizo al invertir tiempo y espacio crítico en el índice, al cual los lectores no acceden sino hasta el final de la lectura, puesto que el mismo está ubicado en la parte trasera del libro en tanto que objeto material. Lo han realizado también, sin embargo, las descripciones de prensa promocionando el texto y la misma contraportada, la cual nos habla de "personajes complejos, que enfrentan la armonía y abundancia de los parajes rurales, pero también la carencia de los recursos en el campo".

Pese a ello la premisa ya explorada hasta cierto punto del matrimonio interétnico no es cualquier cosa. Es una transgresión, y en tanto que tal se contrapone a la visión romántica, armónica, de la idílica comunidad rural admirada de lejos y de forma paternalista, por muchos sujetos cosmopolitas urbanos que suelen yuxtaponerla a la tranquilidad de un fin de semana en su residencia campestre. Recordemos la afirmación de Linda Tuhiwai Smith, según la cual el deseo por una definición simple, pura y no contaminada del nativo indígena por parte del colonizador es generalmente un deseo de poder continuar definiendo al otro (86). El sujeto indígena a cambio busca ser visto como libre, escapar a toda definición, complicarse y mutar, ser reconocido como plenamente humano.

12 Como ya lo señaló, Álvaro Pazos Garciandía, la perspectiva eurocéntrica del sujeto al interior de una comunidad etnificada "[...] presenta a la persona en las sociedades "tradicionales" y "primitivas" como entidad anulada, borrada o reprimida por el peso de la normativa comunitaria. Falta de iniciativa y responsabilidad individual, desajuste de la autoconciencia, identidad fusionada en lo colectivo, no individuación, son algunas de las características, a veces negativa a veces positivamente valoradas, que se han considerado como parte de un marco social y cognitivo más amplio, el de las sociedades y el pensamiento "primitivos" (Pazos 2). 
La transgresión indicada deconstruye esa cadena de significantes armonía/ comunidad/indígena/rural. El texto señala que ésta última restringe el deseo y excluye la posibilidad de agenciamiento. Etimológicamente, una transgresión es cruzar una frontera o demarcamiento que se ha establecido socialmente como tabú. Una infracción denotando falta de tolerancia. Esta última será objeto de una serie de estipulaciones cuyo efecto último es el de modelar la falta de tolerancia codificando la comunidad étnica (aunque esto sea el producto histórico de un legítimo gesto de autopreservación y autodefensa, si bien también lo es de la regimentación colonial) como principio moral subordinando y restrictivo del accionar colectivo. Esta interdependencia radical condicionando todo agenciamiento subjetivo se transforma en el eje definitorio del relato invadiendo los niveles declarativos de quienes hacen cumplir este principio, a saber, los padres de Beto y el padre de Lupe, adquiriendo el mismo una complejidad retórica inesperada como resultado. El texto se erige en consecuencia como mecanismo de oposición y resistencia, cuando no con voluntad de aniquilación, de las jerarquías arcaicas de lo étnico como voluntad de poder.

Ya intuimos, gracias a la enumeración de las partes del texto articuladas en el índice, el posible desenlace del relato. Pero en sus diferentes secuencias, los personajes tienen que confrontar tales hechos en su cotidianidad. Al llegar Beto a casa de sus padres y presentar a Lupe como su esposa, la dejan con la mano tendida como ya lo indicamos con anterioridad. Bajo la presión del tío, quien sí aprueba el matrimonio, sus padres se ven obligados a alojarlos en su casa. Sin embargo, nos dice el texto, "se inició un largo martirio, se mofaban de ella porque no sabía hablar nauatl, le negaban las cosas, a mi hija le pegaban mis hermanas cuando lloraba, comíamos hasta que yo llegaba del trabajo" (182).

Lo anterior genera una espiral descendiente que casi termina deshumanizándolos. Ante el sabotaje constante de su propia familia, la pareja casi desciende a la miseria. Beto recurre al alcohol y a las mujeres para mitigar su impotencia. Lupe aguanta la torturadora cotidianidad con estoicismo. Sin embargo, el padre comienza a ahogarlos financieramente al negarle trabajo a Beto y favorecer a su hijo menor. Finalmente aquel se ve obligado a convertirse en trabajador migrante, donde descubre por primera vez la feroz carga del racismo cuando un capataz le dice: "Indio hijo de la chingada apúrate que crees que viniste a vacacionar o qué" (192). El narrador autodiegético nos informa que "Sentí que me ardió hasta el alma, nunca me habían gritado así..." (192).

La pareja interétnica representa aquí el "exceso" en el sentido de Bataille (1986), desafiando la economía cerrada de la colectividad étnica, a la vez encerrada dentro de una genealogía y de una determinación inmutable. El "exceso" 
arriba señalado anticipa ya lo inasimilable al ubicar las relaciones interétnicas en un primer plano, en una experiencia que implica placer, agenciamiento, empoderamiento. Como decía Foucault (1977), las fronteras del yo y de los espacios culturales están necesariamente iluminadas por actos de transgresión. De allí se desprende el sujeto desestabilizado, el que emerge por medio de la separación entre el individuo y su otredad, la dicotomía otredad/sí mismo en la cual entendemos en este caso otredad en un sentido que no deja de ser paradójico, a saber, como comunidad.

Finalmente la pareja se ve obligada a abandonar la casa de los padres de Beto. De nuevo el tío los protege, llamando a un grupo de faeneros para que los ayuden a construir su casa. La experiencia le sirve a Beto para darse cuenta que "el apoyo mutuo era importante para resolver muchos problemas, $[\ldots]$ y yo, sería yo si colaboraba con el pueblo [...]" (204). Esa realización lo lleva a una reconciliación parcial con sus padres, cuando celebran el rito en el cerro Uilotepetl para tener mejores cosechas (214). Beto decide participar, acompaña a su familia y en la oración es recompensado cuando su padre lo presenta al cerro y le pide que le dé fuerza y ayude a su hijo por ser "él, solo, para crecer, tú, padre, dale sabiduría, tú madre dale amor para que comparta con quien ahora se encuentra y con los que tenga que trabajar, tratar y vivir" (216). Enseguida le enseñan el rito y los mecanismos para realizar la ofrenda. La gestión y el control del conocimiento originario permanecía aún en manos de sus padres, algo sobre lo cual Beto admite que "no entendî" (216). Sus mismas condiciones de posibilidad le habían impedido acceder a este conocimiento dada la proximidad contaminada con su padre. Por ello las estructuras internas del mismo sistema comunitario y su relación con su contexto tradicional, o bien, metafísico cuando no cosmogónico, fueron objeto de tan agresiva y sostenida problematización. Interesantemente, luego de trasmitirle el conocimiento ceremonial, los padres de Beto efectivamente desaparecen de la narración.

La reconstitución del sujeto al interior de la agrupación etnificada es pues valorada, pero ya bajo otros términos. Estos incluirán la castellanización y educación de los hijos de la pareja en un primer momento y su inserción como profesionales en el marco nacional después, sin que con ello se renuncie a su idioma o a sus costumbres, las cuales seguirán marcando su trayectoria y sentir identitario, pese a ser, en efecto y consanguíneamente, "mestizos"y "mestizas"; es decir, portadores de la fetichizada identidad defendida por la retórica de la revolución mexicana como "suya". El texto presupone la comprensión a priori del lector de que la comunidad, en tanto que articulación identitaria, en tanto que totalidad geopolítica que es históricamente un espacio territorial culturalmente articulado 
con cierta integridad ontológica, se encontraba ya deteriorada al inicio mismo del relato (quizás por el bombardeo mismo sufrido por la institucionalización de la revolución a partir de la década de 1920; esa temporalidad histórica precediendo al relato no es articulada discursivamente en momento alguno de lo narrado). $\mathrm{Al}$ interior del relato la comunidad étnica constituía un régimen regularizador necesitado de ser transgredido para que el sujeto pudiera así, por medio del agenciamiento generado por su misma voluntad de poder, reconfigurarla bajo otros parámetros y desde otro posicionamiento alternativo. Beto expropia la injuria y la articula como instrumento transformador. Pero no abandona la sociabilidad comunal. No renuncia a ella. No se convierte en mestizo con vocación y aspiraciones occidentalistas. No abandona su idioma. Asimismo, el relato termina con su nieto Juan, el hijo de su hijo mayor, llevándolo a curarse con un médico espiritual nahua luego de que la medicina occidental fracasó en curarlo (392-398), aunque Lupe, con diabetes avanzada, tiene que ser ingresada en una clínica de la ciudad. Sin embargo, luego de salir de la misma, fue el tomar té de hormigón en la sierra lo que "le dio la sanación" (398).

La figura generalizada de la identidad naua es concebida como una totalidad integral, pese a la introducción de la necesaria discontinuidad por parte del autor, encarnada en la figura del personaje principal. El proceso ontológico de la cerrazón de la colectividad implica, paradójicamente, que esta misma se convierta en la principal amenaza a la funcionalidad de la propia comunidad, su fuente de agotamiento entrópico amenazándola con desaparecer. La trascendencia representada por Beto en su encuentro con Lupe posibilita una nueva regulación y reproducción, produciendo nuevos individuos (los hijos y nietos) aparentemente fundamentales como transferencia de energía regeneradora (por ser mestizos valorando la importancia ética de la preservación de los mecanismos socializantes y sus ritos, y manteniendo un bilingüismo como naua-hablantes). Constituyen una "donación de vida" que excede la temporalidad biológica de los propios progenitores. Garantiza así la sobrevivencia de la indigeneidad. Por ello continúa al interior de la estructura comunal reconocida por los ueues (los principales, las autoridades locales), quienes llegarán a proponerlo como juez de la comarca (308).

En la anterior lógica comprendemos que Beto aprenda a inyectar y se convierta en curandero itinerante sin ser ni farmacéutico occidental ni chamán indígena, sino manteniendo una posición liminal entre ambas posiciones, como sucede a su vez con las curaciones del último capítulo del relato. Siempre hay ese zigzagueo continuo entre las prácticas occidentales y las indígenas. En el caso del trabajo de curandero itinerante, la tarea no se desarrolla sin realizar con 
anterioridad un rito para generarle bienestar en su nuevo oficio (226). En la lógica transgresora tenemos a su vez la celebración del certificado de primaria de $\mathrm{Su}$ sana, la hija mayor (238), seguida de los estudios secundarios para ambos hijos, incluyendo una beca para Susana. Por un lado el texto constata el éxito educativo al afirmar "la mayor entró al bachillerato, el otro [...] se fue a trabajar a la ciudad de México, mientras el tercero, se fue becado a un internado" (274). Asimismo, enfatiza la importancia del costo de la educación, diciéndonos que "el dinero no era suficiente" para pagarle los estudios a todos y hasta tuvieron que vender sapos (260) para obtener los fondos para la educación de los hijos. Los nietos y las nietas reciben a su vez apoyo para estudiar.

Pero por el otro lado, la narratividad misma representa problemáticas contradicciones de género. Cuando la hija volvió de vacaciones "llegó de pantalones" (266). La familia nunca la había visto vestida así. Enseguida tiene un incidente con el padre por las cartas que recibió de varios compañeros. Su padre se enoja, asumiendo lo peor, y la golpea (268). Eso genera un distanciamiento entre ellos que durará hasta su casamiento, ya como maestra profesional. Beto reflexionará entonces que "ella supo enfrentar la vida sin tanta protección porque esa experiencia le había enseñado que debía darse a respetar ante quien fuera" (270).

Aquí el texto nos introduce un elemento periférico al mismo, que no por ello deja de ser crítico: la problemática del género. Beto le articula a la hija el requerimiento de convertirse en aquello que ella ya no es, ya dejó de ser. Su categoría de pater familias intenta regular, controlar y autorizar la subjetividad de su propia hija -como lo hará también con el segundo hijo, a quien le pega por pedirle dinero para curarse cuando está enfermo (272-274)-. Susana rechaza convertirse en alguien legitimada tan solo sobre la base de ser domesticada, una sombra de su realidad. Intuitivamente sabe que hacerlo sería participar en la fantasmática plenitud de una heteronormatividad naturalizadora. Por ello se aleja con el consentimiento tácito de su madre. Son una serie de secuencias periféricas a la centralidad del relato, en cuyo conjunto impera el peso de Beto y su mundo relativamente misógino, pero significativas por evidenciar y representar esa otredad de género en una manera que evidencia el entrenamiento ético al cual el mismo personaje es sometido silenciosa e invisiblemente como tarea sistémica de compromiso epistemológico con la deconstrucción de su opresión. Constituye también un entrenamiento para la imaginación del lector expuesto a los signos y cadenas de significado delatando la misma, una educación estética que posibilita transcender el heterosexismo.

En efecto tenemos representada aquí una educación sentimental, la del propio Beto, desde su gesto transgresor inicial, sus consecuentes dificultades 
para establecerse con su familia y ganarse la vida, hasta su reconocimiento ulterior cuando,

[...] desde ese momento, yo ya no sería un vecino común sino un ueue, por que (sic) mi última función como autoridad había cumplido y debía estar con ellos, abrazaba una responsabilidad más, tomar decisiones serias, claras y concretas. (316)

Desde este punto se desprenden diferentes tipos de ceremonias reconociendo la trayectoria de la familia, desde la celebración de Susana por cumplir quince años de maestra en una misma localidad hasta la llegada de los estudiantes antropólogos de su hijo Carlos, quienes llegan a la región a aprender nauatl y al final de su investigación valoran el pueblo por ser

[...] unido, y son respetados porque se defienden, las respuestas de los jóvenes, indica que siguen los pasos de los grandes, sigan así y serán siempre un pueblo próspero con identidad propia y sin temor a que sus ideas se destruyan, porque cuando un pueblo destruye sus ideas, se destruye por sí solo. (340)

Enseguida el propio Carlos, profesor universitario y ya teniendo 3 hijos con su compañera, quien también es indígena pero "de otra cultura" (344), decide casarse "a la usanza indígena" (342).

En todo este desarrollo volvemos finalmente al título del texto. Este no es gratuito, ya que las últimas líneas del relato vuelven literalmente al mismo. En castellano el texto concluye de manera tersa, luego de un lírico párrafo acerca de "la forma de vida que los abuelos nos enseñaron" (398). Dice tan solo, "Gracias a dios, el tiempo no abortó". Sin embargo en la versión nauatl no existe la separación de la anterior línea del mentado párrafo. La última frase a su vez es "tonali amo tech makajki" (399). Como ya lo indicamos al inicio del artículo, el título oficial en nauatl es "Tonali amo tlanki". en donde "tonali" sería "tiempo, destino, vida, el camino de la vida", "amo" la negación y "tlanki" "terminar", en tiempo pasado simple. Por lo tanto, "el camino de la vida, o el destino, no terminó". Sin embargo "tech makajki" difiere de "tlanki" y de "abortó", rompiendo con la noción de que el texto concluye con la misma frase del título de la obra. "Tech" es el conectivo más general de la lengua náhuatl, implicando "nos". "Makajki" sería "dejó", "abandonó", o bien "no nos alcanzó el tiempo". Al respecto nos dice Amador Ramírez:

$\mathrm{Al}$ decir el tiempo no terminó se entiende también que no nos dejó o abandonó; aquí es donde el simbolismo cobra vida considerando al tiempo como un ser; así el terminar es morir, acabar y si en él estoy, entonces me abandona, 
me deja solo, por que (sic) el tiempo me da la vida; yo formo parte de un todo (universo), así que tonali es tiempo y vida. (Correspondencia con el autor, 11 de febrero 2013)

Por cierto ese último párrafo se inicia en nauatl diciendo "Nopa tonali tlen tech machtijekj to klua ua tik yekojkej" (399). "Tonali", el vocablo denotando "tiempo" en realidad significa literalmente "sol". En las culturas mesoamericanas no existe el concepto de "tiempo", una singularidad inesperada y sorprendente considerando que el aspecto crucial de su cosmovisión es medir precisamente el paso del tiempo. Sin embargo no existe una concepción abstracta que lo denomine en tanto que tal ("sol" es también "día" en varias lenguas mesoamericanas). Tonali aparece aquí entonces como indicador de época, o bien como indicador de la forma debida o apropiada. El último párrafo del texto en nauatl se referiría por consecuencia a la forma debida o apropiada la cual "nos enseñaron nuestros abuelos para que lo vivamos, para que entendamos y para que queramos a la naturaleza aunque pasemos muchas cosas" (399), una variante ligeramente más personalizada de la frase que abre el último párrafo en castellano, la cual dice literalmente "Esa forma de vida que los abuelos nos enseñaron y aprendimos para entender y comprender a la naturaleza" $(398)^{13}$.

Si pareciera que estoy divergiendo de la centralidad de mi argumentación sería porque en esos pequeños detalles localizados en apariencia en las márgenes del análisis encontramos muchas de las claves significativas explicando lo que a primera vista parecería como aparentes descuidos en la traducción al castellano, o bien en la fijación del sentido en nauatl. Pero las cosas podrían no ser tan simples. La figurada negligencia me parece ser en realidad un ocultamiento, una ambigüedad fundante y fundamental. Podría ser descifrado como signos intencionales, como una diligencia secreta, una incitación tramposa tendida al lector monolingüe en castellano. Como hemos visto, tenemos aquí variantes importantes, de nuevo desligándose de la simbología cristiana en la versión nauatl y enfatizándola en la castellana, que pone el sentido último del fin del texto, su explicit siempre cargado de sentido y emotividad y del título mismo de la obra, de cabeza. En la lógica occidentalista esto es desde luego una contradicción. Pero, ¿lo es realmente? Luego del análisis elaborado nos parecería que no es el caso y que en efecto tendríamos las dos cosas a la vez.

13 Agradezco las aclaraciones del nauatl, o náhuatl, a mi colega Sergio Romero, cuya generosidad interviene siempre para facilitar mi comprensión de las lenguas mesoamericanas. 
Dijimos con anterioridad que el actante principal, definido en su viejo sentido semiótico a la Greimas (1983) como la figura o el lugar vacío en que las formas sintácticas o las formas semánticas se vierten, comete una transgresión al casarse con un sujeto extra-comunitario. El matrimonio interétnico constituye una transgresión. Esta transgresión representa, dijimos, el "exceso" desafiando al agrupamiento etnificado y ubicando las relaciones interétnicas en un primer plano. Pero paradójicamente ella instiga a Beto a adquirir la sabiduría necesaria para hacerse miembro integral de la misma. Así, él aprende los ritos e inicia su transición ética hasta terminar siendo un ueue. En esta lógica el tiempo, ese concepto tan disperso, tan desperdigado en los vericuetos del signo catacrésico "tonali", llegó en efecto a su conclusión en tanto que reconfiguró la comunidad luego de incorporar la transgresión como elemento transformador. Esto mismo llegó a ser un nuevo factor articulando la dinámica positiva de la propia colectividad. Pero a su vez no llegó, en el sentido de que el tiempo anterior, el de la economía cerrada, el monolingüismo en nauatl y la limitación matrimonial para miembros del mismo grupo, se rompió. Los viejos parámetros socializantes no llegaron a concluir su "tiempo" en la forma en la cual estaban constituidos y articulados. La nueva forma promete dinamizar a la agrupación etnificada y salvar sus valores pero aún no se ha consolidado. Asimismo, es un modelo inestable y frágil, de naturaleza más virtual, dado que sus miembros se encuentran repartidos por todo el territorio nacional (los familiares viven en diferentes pueblos; algunos en ciudad de México, y hacia el final solo se reúnen para grandes ocasiones; no hay mención de migrantes transnacionales, pero existe también esa posibilidad). Ya no es un conjunto sociocéntrico compartiendo un etnoespacio físico geográficamente demarcado. Es, pues, y ya no es. Es sin ser. Dejó de ser pero aún parece que continúa siendo. Como si lo anterior no fuera ya bastante contradictorio, en su concepción cosmogónica nauatl, el tiempo se marcha sin abandonar a los sujetos porque enseguida aparece un "nuevo" tiempo (otro día, otro año, otro ciclo) que es también el tiempo, una imagen analógica al movimiento de las olas del mar.

Esas son las contradicciones señaladas por el texto. Nada limita a la aldea en tanto que agrupación pero nada la sostiene tampoco en tanto que comunidad, más allá de la voluntad de poder de resguardar sus valores y sistemas de representación. En otras palabras, su discursividad ya no constituye la comunicación de un sentido o dirección específicas, si bien aparenta hacer esto, sino una propagación de lenguajes cuyos sentidos se excluyen mutuamente en partes cruciales para denotar ambigüedades y contradicciones generadas por la misma liminalidad de los sistemas de valores marcando cierta no-existencia en esas oscilaciones a veces brutales cuyos vacíos las propias formas gramaticales designan como realidades 
epistémicas complementarias y contradictorias. Es decir, dos lenguajes diferentes articulando dos exigencias justas pero contradictorias gracias a los silencios generados por el transitar entre ambas lenguas. Sabemos ya que todos los silencios son significativos.

Lo anterior podría parecer como si la narratividad contaminara lo ético, pero a mi modo de ver no lo hace. Privatiza quizás la creencia y el nivel e intensidad de eslabonamiento con la cosmovisión, la asimilación de sus principios metafísicos y epistémicos, pero racionaliza la necesidad de trascender la comunidad cerrada en un mundo inevitablemente globalizado. Si entendemos la colonialidad como un "patrón de poder" que opera a través de la naturalización de jerarquías raciales posibilitando la reproducción de relaciones de dominación territoriales y epistémicas que también subalternizan y obliteran los conocimientos, experiencias y formas de vida de quienes son así dominados y explotados, sabemos que estos sujetos subalternizados y racializados, prácticamente condenados a sobrevivir al interior de castas sociales diferenciadoras de la occidentalidad moderna, no tienen otra alternativa si han de emerger de la condición a la cual han sido condenados mientras luchan simultáneamente por preservar lo fundamental, lo más significativo y valioso de su cosmovisión, su comprensión epistémica del mundo y del cosmos, ese fenómeno denominado "autenticidades en peligro" por Rey Chow (1993).

La ética debe partir, a mi modo de ver, del contexto de los propios grupos humanos subalternizados y racializados, los que han sufrido en su piel y en sus entrañas el imperialismo y el colonialismo desde el renacimiento mismo, convirtiéndose en su "lado oscuro" en palabras de Mignolo (1995). Debe partir de la especificidad de sus condiciones histórico-culturales en tanto que colectividad/comunidad en su más amplia diversidad posible, como instrumento de auto-liberación. En todas ellas se dan aspiraciones concretas para vivir en plenitud. Eso no implica que desaparezcan negatividades dadas las limitaciones de la realidad concreta vivida por sujetos patologizados y proscritos, reducidos en buena medida al servilismo, a ser en efecto "los condenados de la tierra" como lo anunció Fanon (1963) hace ya más de 50 años. No es gratuito por lo tanto, como dijo Eduardo Restrepo, que además de la noción de colonialidad del poder se hable coetáneamente de colonialidad del ser y de colonialidad del saber (292). Lo primero implica la obligatoriedad de las subsiguientes condiciones. El sujeto así colonializado tiene que aprender a defenderse constituyendo modernidades alternativas al interior de sus articulaciones locales. Diversifica así, a través de "juegos de verdad", los centros de resistencia. Asimismo pluraliza, descentra y comprende en su positividad esa otredad que constituye la 
modernidad occidental eurocéntrica sin tampoco aislarse de la misma (ni poder hacerlo aunque quisiera). De nuevo, Restrepo nos recuerda que la idea no es simplemente rechazar la modernidad, la ciencia o la razón bajo el argumento falaz o infantilista de que son culturalmente específicos de la concepción del mundo occidental (294) y en consecuencia, intrínsecamente reproductores de eurocentrismo. Por ello, de hecho, narrativas como las de Amador Ramírez y otros autores indígenas contribuyen más bien a la apertura del cerramiento de Occidente, a obligar a este último a valorar alternativas ontológicas diferenciales en vez de considerar su posicionamiento epistémico como el único válido en la contemporaneidad globalizada.

Todo lo dicho hasta este punto presupone, como recién dijo Gayatri Chakravorty Spivak, que la muerte de la autoridad del autor en tanto que vocero del proceso de establecer exactitud contextual significa a su vez el nacimiento de lectores proponiendo nuevas categorías epistémicas desde sus prácticas de lectura (12). Este giro hacia las problemáticas de lecturas, vinculado con los conflictos y dificultades que conllevan las traducciones desde y hacia idiomas no eurocéntricos, se encuentra presente en la obra reciente de la crítica hindú. Cuáles de estas lecturas emergen en los espacios públicos y cuáles serán autorizadas tiene desde luego implicaciones políticas, dado que quienes realizan estas mismas lecturas se encuentran acosados por el modelo universitario neoliberal, intentando silenciar las humanidades supuestamente por su incapacidad para generar empleos de índole vocacional, pero en realidad, por su enseñanza del pensamiento crítico. Por ello es importante validar no solo estos espacios experimentales que ocupan las narrativas escritas en lenguas indígenas sino el conjunto de este espacio geosocial ocupado por la indigeneidad contemporánea, presuponiendo su mundo como fuente de literariedad. Esto implica una ruptura con la ontología occidentalista y representa planteamientos frescos y estratégicamente críticos de nuevas prácticas decoloniales, rehuyendo la animalidad homogénea que los sectores hegemónicos occidentales le ofrecen al resto del mundo, entendido lo último en el sentido derrideano (The Animal That Therefore I Am) de estar privado de logos, y apelando así al derecho al pensamiento crítico como de manera quizás un tanto más conceptual lo hicieron a su vez el filósofo francés en su libro póstumo y la crítica hindú en la introducción de su última publicación. Leer textualidades indígenas no es en este caso sino la tarea sistémica de la responsabilidad de lo ético coadyuvada por un compromiso epistemológico, apremiado por la necesidad de contaminar mayorías con su intencionalidad para entrenar su imaginación, por mucho que no sea sino un rearreglo de nuestra propia voluntad de poder. 


\section{Obras citadas}

Arias, Arturo. "Nahuahtlizando la novelística: De infiernos, paraísos y rupturas de estereotipos en las prácticas discursivas decoloniales". Alter/nativas 1-29 (2013).

Bakhtin, M. M. Speech Genres and Other Later Essays. Austin: University of Texas Press, 1986.

Balibar, Etienne, e Immanuel Wallerstein. Race, Nation, Class: Ambiguous Identities. Londres: Verso, 1991.

Bataille, Georges. Erotism: Death and Sensuality. Mary Dalwood. Trad. San Francisco: City Lights, 1986.

Butler, Judtih. The Psychic Life of Power: Theories in Subjection. Stanford, CA: Stanford University Press, 1997.

Chow, Rey. Writing Diaspora: Tactics of Intervention in Contemporary Cultural Studies. Bloomington: Indiana University Press, 1993.

Derrida, Jacques. The Animal That Therefore I Am. Marie-Louise Mallet. Ed. Trad. David Wills. Nueva York: Fordham University Press, 2008.

Fanon, Frantz. Los condenados de la tierra. Julieta Campos.

Trad. México: Fondo de Cultura Económica, 1963.

Fernández, Adela. Dioses Prehispánicos de México. México: Panorama Editorial, 1998. Foucault, Michael. "A Preface to Transgression". Language, CounterMemory, Practice: Selected Essays and Interviews. Donald F. Bouchard. Ed. Ithaca, NY: Cornell University Press, 1977. 29-52.

Genette, Gérard. Paratexts: Thresholds of interpretation. Richard Macksey. Trad. Cambridge: Cambridge University Press, 1997.

Greimas, A. J. Structural Semantics: An Attempt at a Method. Daniele McDowell, Ronald Schleifer y Alan Velie Trads. Lincoln, NE: University of Nebraska Press, 1983.

Hale, Charles R. "El discurso ladino del racismo al revés en Guatemala", ¿'Racismo en Guatemala? Abriendo el debate sobre un tema tabú. Clara Arenas, Charles Hale y Gustavo Palma Murga. Eds. Guatemala: AVANCSO, 1999 361-444.

León-Portilla, Miguel. La filosofía náhuatl estudiada en sus fuentes. México: UNAM, 2006.

Mignolo, Walter D. The Darker Side of the Renaissance: Literacy, Territoriality, \& Colonization. Ann Arbor: University of Michigan Press, 1995

Notimex. "Presenta Amador Ramírez su libro escrito en español y náhuatl". Notimex (2011, miércoles 2 marzo): 17: 42. Disponible en http://www.sdpnoticias.com/ notas/2011/03/o2/presenta-amador-ramirez-su-libro-escrito-en-espanol-y-nahuatl

Pazos Garciandía, Álvaro. "El otro como sí-mismo: Observaciones antropológicas sobre las tecnologías de la subjetividad". AIBR. Revista de Antropología 
Iberoamericana, Núm. Especial (Noviembre-Diciembre 2005). <http://

www.aibr.org/antropologia/44nov/articulos/nov0503.pdfs

Ramírez, Crispín Amador. Tlajtolchiuali, Palabra en movimiento:

El verbo. Toluca: Instituto Mexiquense de Cultura, 2002.

-. El tiempo no abortó/Tonali Amo Tlanki. Toluca:

Instituto Mexiquense de Cultura, 2008.

Restrepo. Eduardo. "Antropología y colonialidad". El giro decolonial: Reflexiones para una diversidad epistémica más allá del capitalismo global. Castro-Gómez, Santiago y Ramón Grosfoguel Eds. Bogotá: Siglo del Hombre Editores, 2007. 289-304.

Romero, Sergio. "On literacy, language and ethnicity: Writing and identity among the Q'eqchi' Maya". Manuscrito.

Schwab, Gabriele. The Mirror and the Killer Queen: Otherness in Literary Language. Bloomington: Indiana University Press, 1996.

-. Imaginary Ethnographies: Literature, Culture \& Subjectivity. Nueva York: Columbia University Press, 2012.

Scott Momaday, N. House Made of Dawn. Nueva York: Harper \& Row, 1968.

Smith, Linda Tuhiwai. "On Tricky Ground: Researching the Native in the Age of Uncertainty". The SAGE Handbook of Qualitative Research. Norman K. Denzin e Yvonna S. Lincoln, Eds. Thousand Oaks, CA: Sage, 2005. 85-107.

Sommer, Doris. "Rigoberta's Secrets". Latin American Perspectives 18. 3 (Summer, 1991): 32-50.

Spivak, Gayatri Chakravorty. An Aesthetic Education in the Era of Globalization. Cambridge: Harvard University Press, 2012.

Vargas Llosa, Mario. La utopía arcaica: Fosé María Arguedas y las ficciones del indigenismo. México: Fondo de Cultura Económica, 1996. 